\title{
Examining bed-bath practices of critically ill patients
}

\author{
Azza H. El-Soussi, Hayam I. Asfour * \\ Department of Critical Care and Emergency Nursing, Faculty of Nursing, Alexandria University, Alexandria, Egypt
}

Received: May 10, 2016

DOI: $10.5430 /$ jnep.v6n12p1
Accepted: June 28, 2016

Online Published: July 17, 2016

URL: http://dx.doi.org/10.5430/jnep.v6n12p1

\begin{abstract}
Introduction: Daily bed-baths are usually provided for most critically ill patients to improve patient hygiene, promote comfort and improve health outcomes. Critically ill patients are at greater risk for skin colonization and infection with multidrug-resistant organisms. Therefore, it is important to provide critically ill patient with effective personal hygiene especially bed-bath as poor hygiene may increase the risk of infection. The decision for bed-bath depends on the judgment of the caring nurse. The aim of this work was to describe bed-bath practices in intensive care units.

Methods: A descriptive design was used. Sixty intensive care unit nurses were involved. Tool: "Bed-bath practices of critically ill patients' assessment sheet" was used to collect data.

Results: More than three quarters of nurses, $79 \%$ had improper bed-bath practices. The gap for safe bed-bath practices between nurses' current bed-bath practices and the bed-bath evidence-based recommendations is wide (83\%). Nurses' self-reported reasons that hinder safe bed-bath practices were financial resources, followed by lack of equipment, no policy, lack of knowledge, and workload.

Conclusions: Although, bed-bath is a routine nursing procedure, critical care nurses in the current study had poor skills and knowledge regarding it. The factors affecting bed-bath practice are financial resources, lack of equipment, no policy, lack of knowledge and workload. In-service training program should be conducted for nurses regarding putting priority of nursing care, determining timing and frequency for the bed-bath.
\end{abstract}

Key Words: Bed-bath practices, Nursing practices, Critically ill patients, Intensive care units

\section{INTRODUCTION}

Hygiene is important to maintain health. Personal hygiene is the self-care by which people attend to such functions as toileting, bathing, grooming, and general body hygiene. Patients in intensive care units (ICUs) are at greater risk for skin colonization and infection with multidrug-resistant organisms (MDROs) because of the presence of significant comorbidities, immunodeficiency, exposure to antibiotics, and breaks in skin integrity related to the use of invasive devices. Therefore, it is important to provide critically ill patient with effective personal hygiene as poor hygiene may increase the risk of infection. ${ }^{[1,2]}$

Daily bed-baths are usually provided for most critically ill patients to improve patient hygiene, promote comfort and improve health outcomes. Although bed-bath effectiveness at reducing bacterial colonization is questionable, many clinical goals may be achieved by bed-bath such as inducing comfort, relaxation, stimulating the circulation, providing a chance for skin assessment and reducing pyrexia. Personal hygiene is closely related to an individual's esteem and sense of wellbeing. ${ }^{[1,2]}$

Prioritizing hygiene in the face of a critically ill and unstable

\footnotetext{
* Correspondence: Hayam I. Asfour; Email: hayamasfour2002@gmail.com; Address: Department of Critical Care and Emergency Nursing, Faculty of Nursing, Alexandria University, Alexandria, Egypt.
} 
patient is a challenging clinical mystery. In some instances, the maximization of sleep, hemodynamic stability and good temperature regulation may have greater clinical importance. The frequency of bed-bath should be individualized and depends on personal preference and factors such as the patient's level of stability, pyrexia, and continence. Being sedated and mechanically ventilated, most critically ill patients cannot voice their bathing needs. ${ }^{[3-6]}$

The decision for bed-bath depends on the judgment of the caring nurse. A patient bed-bath may be performed as a nursing routine and is affected by nursing workload instead of considering patient's hygienic needs. In the ICU environment, the provision of a daily bed-bath is an established acceptable practice. However, bed-bath timing differences can be observed from health facility to health facility and from nurse to nurse. In several studies, the majority of bedbaths occur during the early hours of the morning. Studies reported that bed-bath is performed during the hours of 24:00 and 05:00. Therefore, it is suggested that bed-bath should be timed so as not to disrupt patient's sleep. ${ }^{[2-5]}$

Nurses have two basic options for bathing adult patients: the traditional basin bath method using soap and water and/or chlorhexidine gluconate (CHG) solution, or bathing using pre-moistened cloths containing a cleaning agent or CHG. ${ }^{[6-8]}$ Literature offers support for the use of disposable bed-baths over traditional basin bed-baths. Studies revealed that nurses expressed a clear preference for the disposable bath. Several studies have shown a significant decrease in healthcare-associated infections (HAIs) from daily use of CHG bed-bath, and extensive research supports the use of CHG bed-bath over soap and water. ${ }^{[6-8]}$ For patients with dry skin, use of a topical emollient is supported by several studies to maintain skin integrity and its function. In addition, nurses may rub patients' skin during bathing which may predispose patients to infections. ${ }^{[7-11]}$

Bed-bath can be a pleasant or stressful experience; for some patients, a bath is a source of pleasure, while for others, it may be understood as an aggressive behavior that causes distress or fear. Many patients experience fear, anxiety, and frustration related to the techniques used in bed-bath, which are selected according to nurses' judgment not to patient needs and preferences. Nurses should not try to force their own standards of hygiene. ${ }^{[2-5]}$

Bed-bath is an intervention that should be performed with strict monitoring and control, especially in critically ill patients, for whom it is necessary to avoid adverse events, such as ventilator disconnection and hemodynamic instability, among others. During bathing or an hour later many adverse events may occur such as, desaturation, intracranial hypertension, mechanical ventilation disconnection, abnormal heart rate, changes in blood pressure, oxygen saturation, pulmonary wedge pressure, ventricular fibrillation, and cardiac arrest. ${ }^{[7-11]}$

However, bed-bath is considered as unattractive procedure because it is distasteful, repetitive, and physically demanding tasks. Nurses often delegate bed-bath to assistants and/or novice staff. In addition, the prioritization of hygienic measures for a critical patient is challenging to nursing professionals. In some cases, hemodynamic stability, sleep disruption and temperature regulation might be more relevant to the patient's clinical condition. It is reported by researches that in critically ill patients, more adverse events occur mainly during bed-bath or an hour later. ${ }^{[7-11]}$ Therefore, the aim of this work was to describe bathing practices in intensive care units.

\subsection{Aim of the work}

To describe bathing practices in intensive care units.

\subsection{Question of this study}

- What are the bed-bath practices in intensive care units?

- What are the factors affecting bed-bath practices in intensive care units?

\section{MATERIALS AND METHOD}

\subsection{Research design}

A descriptive design was used.

\subsection{Setting}

This study was carried out in two ICUs at a selected hospital in Alexandria-Egypt. All of the ICUs follow the same infection control policies and procedures. There is no specific technique for bed-bath in the units as they perform bed-bath using soap \& water, and nurses used to rub patients' skin during bed-bath. However, there is a policy in the unit to let patients sleep during night and keep 4 hours from 2-6 a.m. free from any nursing activities unless patients' needs such as suctioning. Nurses also have to clean their patients before the end of the shift-there are three shifts in the units. In addition, the availability of health care assistants (non-nursing staff) who are assigned to assist in bathing (perform bathing with nurses) and help in equipment holding for patient safety (e.g., central venous line, the endotracheal tube, etc.).

\subsection{Subjects}

A convenience sample of 60 nurses involved in providing direct care to critically ill patients in the previously mentioned ICUs were included in this study. Nurses less than a year ICU experience and intern nurses were included in the 
study. Nurses may be assigned to care for one patient or two patients according to patients' severity.

Tool: "Bed-bath practices of critically ill patients' assessment sheet": The researchers developed this tool after reviewing the related literatures. ${ }^{[2-12]}$ It was used to describe bathing practices performed for critically ill patients. It consists of three parts:

Part 1: Bed-bath practices observational checklist. This tool was used to observe bed-bath practices provided for critically ill patients. The checklist was developed based on the evidence-based adult patient bed-bath guidelines of the American Association of critical care nurses (AACN). ${ }^{[13]}$ It contained several main items describing bed-bath practices which are: frequency, timing, duration, equipment used for bed-bath procedure such as basins (reusable/disposable), types of cleansers and technique of bed-bath.

Scoring system: Steps of bed-bath practices were measured using a scale of "C", or " $\mathrm{N}$ " depending if the elements of care have been applied; $\mathrm{C}$ if the element criteria is compliant (C $=2)$ and $\mathrm{N}$ when the element criteria is non-compliant ( $\mathrm{N}=$ 1). The score range is 12-24. Proper practice was considered when the score was 16 or more, while improper practice was considered when the score was less than 16 .

Part 2: "ICU nurses' gap analysis for bed-bath practices of critically ill patients". This part of the tool is a questionnaire used for nurses to help them reporting the current bed-bath practices performed in ICUs. It comprises ten items related to critically ill patients' bed-bath practices. The items were classified according to the bed-bath procedure. The items are:

- Assessment; frequency timing, and duration of bedbath (making bath time patient-centered).

- Equipment used in bed-bath (each patient has his own equipment [as basins], re-using basins for bathing patients, basins are disposed after the patients' discharge, using prepackaged baths, using tap water when bathing patients, using a no-rinse, ph-balanced cleanser, bathing patients with CHG, and applying an emollient after bathing).

- Technique of bed-bath (rubbing vigorously over skin).

Scoring system: For each item has a five Likert scale ranging from one to five in which one is the lowest score and five is the highest score. In the following items making bath time patient-centered nurses, each patient has his own equipment (as basins), basins are disposed after the patients' discharge, using prepackaged baths, using a no-rinse, phbalanced cleanser, applying an emollient after bathing and bathing patients with $\mathrm{CHG}$, the score is ranging from (always $=5$, usually $=4$, often $=3$, sometimes $=2$ to never $=1$ ).

While the scale is reversed in three items; re-using basins for bathing patients, using tap water when bathing patients, and rubbing vigorously over skin, as the scale was ranging from (never $=5$, sometimes $=4$, often $=3$, usually $=2$ to always $=1)$. Total responses for all items were 50 score equal to $(100 \%)$. The possible score range was 10 to 50 . When the score was 35 or more, this indicates that the gap for safe bathing is narrow, while the low score (less than 35) indicates that the gap for safe bathing is wide.

In addition to the critical, care nurses' characteristics such as age, sex, educational level, marital status, income and experience in intensive care.

Part 3: ICU nurses' self-reported reasons that hinder safe bed-bath practices. Data in this tool were collected through a structured interview schedule. This tool is used to identify nurses' self-reported reasons that hinder safe bed-bath practices in ICUs. This tool involves the same items involved in bed-bath procedure, which are frequency, timing, duration, equipment, used for bed-bath procedure such as basins (reusable/disposable), types of cleansers and technique of bed-bath. The reasons are classified into organizational and patient related reasons. Organizational related reasons are absence of bed-bath policy in the unit, lack of equipment and supplies, and conflict between the need to provide care and provide other important nursing measures, lack of knowledge, workload, lack of nursing personnel and financial resources. The patient related reasons are presence of incontinence; diaphoresis; post procedure/post-surgery; freshen-up and patients' discomfort.

Scoring system: The response format was a three point Likert scale ranging from one to three, representing the extent to which the item was a reason that hinder safe bed-bath practices in ICUs $(1=$ no extent, $2=$ a moderate extent, 3 $=\mathrm{a}$ great extent). All responses were ranked according to their effect in hindering safe bed-bath practices in ICUs as reported by nurses.

\section{Tools validity and reliability}

The current study tools were submitted to five academic nursing experts in the critical care \& emergency nursing to test the face and content validity of the tool, the necessary modifications were carried out according to the academic nursing experts' judgment on clarity of sentences and the appropriateness of the content. The tool reliability was tested using internal consistency methods (Alpha Cronbach test). Its result was 0.926 , which indicates an accepted reliability of the tool. 


\subsection{Pilot study}

A pilot study was conducted on five (12\%) nurses. Nurses were recruited from the previously mentioned study settings to assess the current study tool for its clarity, validity, and applicability. Necessary modifications of the tool was done according to pilot results to reach the finalized form. The subjects who included in the pilot study were excluded from the total study sample.

\subsection{Procedure}

The study was achieved through two phases namely; observation and interview phase. The researchers began with introducing themselves and providing clear explanation about the nature, aim and purpose of the current study to the nurses. Each nurse was informed that sharing in this study is voluntary. Collection of the required data were carried out through observing and meeting with the participated nurses. Data collection took 6 months: from the beginning of October 2011 to the end of March 2012.

\subsubsection{The observation phase}

The purpose of this phase was to collect data regarding bedbath practices performed in critical care units. Two research assistants from the Faculty of Nursing, Alexandria University, Egypt served as observers of nurses' practices in the ICUs. One of the researchers trained these observers. Training on observations were conducted onsite in the two ICUs for a week before the start of the study, using the predesigned observation form (part 1 of the tool). Observers were instructed to not interfere with the delivery of care. The observers were rotated between the two ICUs.

Inter-observer consistency more than $90 \%$ was confirmed before the start of observation phase. Then, the researchers/research assistants went to the critical care units daily, for $24 \mathrm{hrs}$. Information was collected by one or two observers per shift ( 8 a.m. to 2 p.m., 2p.m. to 8 p.m., 8 p.m. to 8 a.m.) for each ICU. Each nurse was observed three times for each item of bed-bath; once every (evening, night, morning shift) using part I of the tool. In addition, data related to demographic factors and nurses' characteristics, including age, sex were collected.

\subsubsection{The interview phase}

This phase began after the observation phase to avoid contamination of data. The purpose of this phase was to collect data regarding bed-bath practices of critically ill patients and nurses' related reasons that hinder safe bed-bath practices. Nurses were informed (oral and written) about the aim of the study. Critical care nurses were interviewed on an individual basis during the break time in the morning and/or evening shift to identify the extent of the gap for safe bed-bath prac- tices through answering questions using part 2 of the tool. In addition, nurses self-reported reasons that hinder safe bedbath practices were collected using part 3 of the tool. Time spent for each interview ranged from 25 to 30 minutes using the previously stated tool in their break time.

\subsection{Administrative design and ethical considerations}

The study conducted over a period of 6 months from the beginning of October 2011 to the end of March 2012. An official letter clarifying the purpose and setting of the study was obtained from the ethical committee the head of Critical Care \& Emergency Nursing Department, Nursing Faculty University of Alexandria and from the hospital administrative authority to conduct the study. Each nurse was informed about the significant and aim of the study and then an informed written consent was obtained from each nurse before participating in the study. The anonymity, the confidentiality, and the right to refuse to participate and/or withdraw from the study were assured.

\subsection{Statistical analysis}

The raw data were coded and transformed into coding sheets. The results were checked. Then, the data were entered into SPSS system files (SPSS package version 17) using personal computer. Output drafts were checked against the revised coded data for typing and spelling mistakes. Finally, analysis and interpretation of data were conducted. The following statistical measures were used: Descriptive statistics including frequency, distribution, mean, and standard deviation were used to describe different characteristics. KolmogorovSmirnov test was used to examine the normality of data distribution. Univariate analyses including: $t$-test was used to test the significance of results of quantitative variables. Moreover, Chi-Square test and Fisher's exact test were used to test the significance of results of qualitative variables. A significant $p$-value was considered when $p$ less than 05 .

\section{RESUlTS}

Table 1 shows nurses distribution according to their demographic data. It was noted that more than half of nurses (62\%) were less than 25 years old, and three quarters of nurses were females. Regarding nurses' level of education, it was noted that nearly two thirds of nurses $(65 \%)$ had bachelor degree. Around two thirds of nurses $(65 \%)$ had ICU work experience less than five years.

Tables 2 and 3 show the distribution of nurses according to their level of bed-bath practices. Table 2 shows the frequency, timing and duration of bed-bath. It was noted that nearly three quarters $(73 \%)$ of nurses performed bed-bath for each patient three times a day. As for timing of bed-bath, it was 
observed that all nurses performed bed-bath at 6 a.m. and $70 \%$ of nurses performed bed-bath for the second time at 6 p.m. Eighty percent of nurses took up to 20 minutes in performing bed-bath practices.

Table 1. Distribution of studied nurses according to demographic data

\begin{tabular}{lll}
\hline Demographic & $\mathbf{N}$ & $\mathbf{\%}$ \\
\hline Age & 37 & 62 \\
$<25$ & 20 & 34 \\
$25-30$ & 3 & 5 \\
$31-35$ & & \\
Gender & 15 & 25 \\
Male & 45 & 75 \\
Female & & \\
Level Education & 21 & 35 \\
Diploma & 39 & 63 \\
BSc in nursing & & \\
Year Experience & 20 & 33 \\
$<1$ y & 19 & 33 \\
$1-<5$ & 14 & 23 \\
$5-<10$ & 5 & 8 \\
$10-<15$ & 2 & 3 \\
$\geq 15$ & &
\end{tabular}

In Table 3, it was observed that more than three quarters of nurses $(79 \%)$ had improper bed-bath practices. More than a quarter of nurses $(27 \%)$ determined bath time by patient clinical stability. It was also noted that more than three quarters of nurses $(77 \%)$ took into considerations the patients' physiologic tolerance to bathing. As for skin inspection, it was done by $15 \%$ of nurses only. All nurses use re-usable basins for patients' bathing where the same basins used for all patients. Tap water was used for bed-bath. Chlorhexidine gluconate $(\mathrm{CHG})$ and prepackaged bathing products were not used in bathing. Soap and water were used in bathing. Eighty five percent of nurses rub vigorously over skin while only $8 \%$ of nurses applied emollients after each bath. As for doc- umentation of the procedure, only $5 \%$ of nurses documented bed-bath procedure.

Table 2. Frequency, timing and duration bed-bath in ICUs

\begin{tabular}{ll}
\hline Items & \% of nurses \\
\hline Frequency of bathing/day & \\
Three times & 73 \\
Two times & 15 \\
Once & 12 \\
Timing of bathing & \\
6 a.m. & 100 \\
6 p.m. & 70 \\
1 p.m. & 10 \\
Duration/minutes & \\
$>20$ & 12 \\
$15-20$ & 80 \\
$<15$ & 8 \\
\hline
\end{tabular}

The gap for safe bed-bath practices between nurses' current bed-bath practices and the bed-bath evidence-based recommendations is wide ( $83 \%$ ) as Table 4 revealed. The majority of nurses $(97 \%)$ revealed that they made bath time patient centered and $37 \%$ of nurses stated that they applied an emollient after bathing. All nurses stated that they used tap water for bathing and did not use $\mathrm{CHG}$ for bathing. The majority of nurses $(95 \%, 97 \%, 95 \%, 92 \%, 93 \%, 88 \%)$ had poor bedbath practices as they stated that: not every patient had his own equipment (as basins), basins were re-used for bathing patients and basins were not disposed after the patients' discharge. Prepackaged baths were not available, a no-rinse, ph-balanced cleanser was not used, and sometimes, they used to rub the skin vigorously respectively. The difference between nurses' level of practice and nurses' gap analysis for bed-bath practices of critically ill patients was statistically significant at $p<.05$. (The chi-square statistic is 5.2164. The $p$-value is .0223).

Table 3. Distribution of nurses according to their level of bed-bath practices

\begin{tabular}{|c|c|c|c|c|c|}
\hline \multirow{3}{*}{ Bed-bath practice items } & & \multicolumn{4}{|c|}{ Total $(\mathrm{N}=60)$} \\
\hline & & \multicolumn{2}{|c|}{ Proper } & \multicolumn{2}{|c|}{ Improper } \\
\hline & & $\mathbf{N}$ & $\%$ & $\mathbf{N}$ & $\%$ \\
\hline \multirow{4}{*}{ Assessment } & $\begin{array}{l}\text { - Determine bath time by patient clinical stability versus unit or nurse } \\
\text { organizational factors }\end{array}$ & 16 & 27 & 44 & 73 \\
\hline & - Avoid bathing between the hours of 24:00 and 6:00 & 57 & 95 & 3 & 5 \\
\hline & - Consider the patients' physiologic tolerance to bathing & 46 & 77 & 14 & 23 \\
\hline & - Skin inspection & 9 & 15 & 51 & 85 \\
\hline \multirow{5}{*}{ Equipment } & - Use disposable basins instead of re-usable basins & 0 & 0 & 60 & 100 \\
\hline & - Use sterile or distilled water in place of tap water & 0 & 0 & 60 & 100 \\
\hline & - Use no-rinse pH-balanced cleansers & 6 & 10 & 54 & 90 \\
\hline & - Bathe daily with chlorhexidine gluconate (CHG) & 0 & 0 & 60 & 100 \\
\hline & - Use prepackaged bathing products & 0 & 0 & 60 & 100 \\
\hline Technique of bathing & - Do not rub vigorously over skin & 9 & 15 & 51 & 85 \\
\hline \multirow{3}{*}{ Post bathing } & - Apply emollients after each bath & 5 & 8 & 55 & 92 \\
\hline & - Documentation & 3 & 5 & 57 & 95 \\
\hline & Total & 151 & 21 & 569 & 79 \\
\hline
\end{tabular}


Table 4. ICU nurses' gap analysis for bed-bath practices of critically ill patients

\begin{tabular}{|c|c|c|c|c|}
\hline \multirow{3}{*}{ Bed-bath practice items } & \multicolumn{4}{|c|}{ Total $\mathbf{N}=60$} \\
\hline & \multicolumn{2}{|c|}{ Narrow } & \multicolumn{2}{|c|}{ Wide } \\
\hline & No. & $\%$ & No. & $\%$ \\
\hline Making bath time patient-centered & 58 & 97 & 2 & 3 \\
\hline \multicolumn{5}{|l|}{ Using reusable bath basins } \\
\hline - Each patient has his own equipment (as basins) & 3 & 5 & 57 & 95 \\
\hline - Avoid re-using basins for bathing patients & 2 & 3 & 58 & 97 \\
\hline - Basins are disposed after the patients' discharge & 3 & 5 & 57 & 95 \\
\hline Using tap water when bathing patients & 0 & 0.0 & 60 & 100 \\
\hline Bathing patients with CHG & 0 & 0 & 60 & 100 \\
\hline Using a no-rinse, pH-balanced cleanser & 4 & 5 & 56 & 94 \\
\hline Using prepackaged baths & 5 & 8 & 55 & 92 \\
\hline Avoid rubbing vigorously over skin & 7 & 12 & 53 & 88 \\
\hline Applying an emollient after bathing & 22 & 37 & 38 & 63 \\
\hline Total & 104 & 17 & 496 & 83 \\
\hline
\end{tabular}

Table 5 shows ICU nurses' self-reported reasons that hinder safe bed-bath practices. The most common reason stated by nurses was financial resources, followed by lack of equip- ment, no policy; lack of knowledge, workload and the least reason was that the procedure is not comfortable for patients.

Table 5. ICU nurses' self-reported reasons that hinder safe bed-bath practices

\begin{tabular}{|c|c|c|c|c|c|c|c|c|c|c|c|c|}
\hline \multirow{3}{*}{ Bed-bath practices } & \multicolumn{12}{|c|}{ Reasons that hinder safe bed-bath practices $(\mathrm{N}=60)$} \\
\hline & \multicolumn{2}{|c|}{ No policy } & \multicolumn{2}{|c|}{$\begin{array}{l}\text { Lack of } \\
\text { equipment }\end{array}$} & \multicolumn{2}{|c|}{$\begin{array}{l}\text { Not comfortable } \\
\text { for patients }\end{array}$} & \multicolumn{2}{|c|}{$\begin{array}{l}\text { Financial } \\
\text { resources }\end{array}$} & \multicolumn{2}{|c|}{$\begin{array}{l}\text { Lack of } \\
\text { knowledge }\end{array}$} & \multicolumn{2}{|c|}{ Workload } \\
\hline & No & $\%$ & No & $\%$ & No & $\%$ & No & $\%$ & No & $\%$ & No & $\%$ \\
\hline Making bath time patient-centered & 2 & 3 & 0 & 0.0 & 0 & 0.0 & 0 & 0.0 & 0 & 0.0 & 3 & 5 \\
\hline $\begin{array}{l}\text { Using reusable bath basins } \\
\text { Each patient has his own equipment (as basins) }\end{array}$ & 60 & 100 & 60 & 100 & 0 & 0.0 & 60 & 100 & 0 & 0.0 & 0 & 0.0 \\
\hline Avoid re-using basins for bathing patients & 60 & 100 & 60 & 100 & 0 & 0.0 & 60 & 100 & 0 & 0.0 & 0 & 0.0 \\
\hline Basins are disposed after the patients' discharge & 60 & 100 & 60 & 100 & 0 & 0.0 & 60 & 100 & 30 & 50 & 0 & 0.0 \\
\hline Using tap water when bathing patients & 60 & 100 & 50 & 83 & 0 & 0.0 & 60 & 100 & 0 & 0.0 & 0 & 0.0 \\
\hline Using prepackaged baths & 60 & 100 & 60 & 100 & 1 & 1.67 & 60 & 100 & 15 & 25 & 1 & 1.67 \\
\hline Using a no-rinse, pH-balanced cleanser & 14 & 23 & 6 & 10 & 0 & 0.0 & 60 & 100 & 23 & 38 & 1 & 1.67 \\
\hline Avoid rubbing vigorously over skin & 0 & 0.0 & 0 & 0.0 & 0 & 0.0 & 0 & 0.0 & 11 & 18 & 0 & 0.0 \\
\hline Applying an emollient after bathing & 0 & 0.0 & 20 & 33 & 0 & 0.0 & 30 & 50 & 0 & 0.0 & 0 & 0.0 \\
\hline Bathing patients with CHG & 13 & 22 & 20 & 33 & 1 & 1.67 & 60 & 100 & 50 & 83 & 1 & 1.67 \\
\hline Skin inspection & 0 & 0.0 & 0 & 0.0 & 0 & 0.0 & 0 & 0.0 & 5 & 8 & 50 & 83 \\
\hline Total number & 329 & & 336 & & 1 & & 450 & & 134 & & 56 & \\
\hline Ranking & 3 & & 2 & & 6 & & 1 & & 4 & & 5 & \\
\hline
\end{tabular}

\section{Discussion}

\subsection{Description of bed-bath in ICUs}

Vulnerable skin is more prone to damage, and infection. Bathing the critically ill can result in significant variations such as extremely dry skin, greater nursing time, and the potential for colonization of the skin and the spread of microorganism. Critically ill patients are unable to provide self-care and critically ill patients are unable to perform self-care because of many reasons such as decrease level of consciousness, sedation and mechanical ventilation. ${ }^{[1-3,12]}$

\section{Frequency, timing and duration bed-bath in ICUs}

In the current study, the majority of nurses performed bedbath three times/day. Little literature exists on the frequency of bed-bath. However, Coyer et al. $(2011)^{[2]}$ conducted an exploratory study on bed-bathing performed to critically ill patients, and showed that $37.5 \%$ of all bed baths were routine daily baths.

It is acceptable that nurses provide bed-bath for critically ill 
patients at least once daily. However, bed-bath should be performed according to patients' needs such as for comfort to reduce anxiety, or for cleanliness to respond to diaphoresis, or incontinence. In the current study, patients had bed-bath once/shift (12 or $8 \mathrm{hrs}$.); nurses were performing bed-bath once/shift as a nursing routine and according to ICU policy.

Bed-bath is associated with an increase in oxygen consumption. The current study revealed that nurses took into consideration patients' physiologic tolerance to bathing. This result is in agreement with the AACN guidelines who recommends that patients' physiologic tolerance to the activity should be considered when determining optimal time for bed-bath. ${ }^{[13]}$ However, a study of Sereika et al. (2011) ${ }^{[12]}$ on weaning trial days, the researchers found a longer weaning trial (average 3 hours) when the bath is given during weaning. During bed-bath, patients may remain in supine position, which may decreases ventilation and causes hypoxemia. In addition, during bathing, nurses may be unable to observe patients hemodynamic state accurately.

Bed-bath may be performed according to the suitability of nursing routine or workload without considering patients hygiene needs. In the current study, time of bed-bath for patients was at 6 a.m., 1 p.m. and 6 p.m. and the majority of patients had bed-bath at 6 a.m. and 6 p.m. However, Coyer et al. $(2011)^{[2]}$ found that a routine bath was given between 2 a.m. and 6 a.m. in $30 \%$ of bed-bath episodes. Celik et $a l .{ }^{[3]}$ reported that bed-bath, as one of the nursing activities was more frequent during the hours of 24:00 and 5:00. In the same line, Tamburri et al. ${ }^{[5]}$ examined nocturnal care in the ICU, and found that $61 \%$ of patients were performed on a routine daily bed-bath between 2 and 5 a.m.

The AACN guidelines suggest that bed-bath should be timed so as not to disrupt or negatively influence patients' sleep. ${ }^{[13]}$ Therefore, bed-bath between the hours of 24:00 and 6 a.m. should be avoided to allow for uninterrupted sleep, unless a clinical condition warrants cleansing, or the patient requests a bath. The result of the current study is attributed to ICU policy, which restricts any nursing activities performed for patients between 24:00 and 6 a.m. unless patients' needs. In addition, the availability of patient care assistants (nonnursing staff) who were assigned to assist with bed-bath and equipment holding for patient safety (e.g., central venous line, the endotracheal tube, etc.) is in the late afternoon and early morning. Another reason is that nurses may want to handle over a clean patient.

Many studies did not present the duration of bed bathing. From the current study findings, it was noted that, eighty percent of bed- bath performed by nurses took 15-20 min. However, based on the records of some studies that published the bathing time variable, the global average total bathing time was calculated as 20 minutes and 14 seconds. ${ }^{[2,7,14]}$ In a study aimed to compare the traditional basin bed bath with a prepackaged disposable bed bath in terms of time and quality of bath, the researchers found that the mean bath times were 12.8 minutes for disposable baths and 14.4 minutes for traditional baths. ${ }^{[7]}$ In Coyer et al. ${ }^{[2]}$ study, bed-bath took 15-30 min to complete.

\subsection{Equipment used for bed-bath}

\subsubsection{Basins}

When patients cannot take a bath themselves, they are often given a bed bath using a basin. The primary objective for bed-bath is restoring cleanliness. From the results of the current study, it was observed that: nurses used basins for bed-bath, and basins were reused for all patients. Nurses learned bed-bath as an important basic procedure for maintain patients' cleanliness and comfort. However, evidence suggests that use of basins in hospitals may be sources for many potential hospital-acquired infections (HAIs) ${ }^{\left[{ }^{[8]}\right.}$

Patients' bath basins are considered as a reservoir for bacteria and a possible source of infection for high-risk patients as reported Johnson et al. (2009) ${ }^{[8]}$ in their study. Johnson et al evaluated 92 bath basins from three ICUs in acute care hospitals. After the water had been emptied and the basin were allowed to air-dry, nurses obtained culture specimens using sterile sponges, at least 2 hours after patient bed-bath. All basins used for only one patient and were disposable. The specimens were sent to an outside lab for microbial testing. The researchers found bacteria in $98 \%$ of basins. Highest bacterial growth rates were $54 \%$ enterococci, $32 \%$ gram-negative bacilli, 23\% staphylococcus aureus, and $13 \%$ vancomycin-resistant enterococci. ${ }^{[8]}$

In another multicenter study, Marchaim et al. (2011) ${ }^{[9]}$ took samples from basins in 88 hospitals and found $62.2 \%$ of 1,103 basins sampled were contaminated with common hospital-associated pathogens. The highest contamination rate was for gram-negative bacilli (44.9\%) followed by vancomycin-resistant enterococci (34.9\%). The lowest was MRSA with a 3.3\% rate. Studies reported that contamination of basins occurs through many sources, including the patient's skin flora, bacterial biofilm in the tap water, basins used for incontinence cleansing, storage of hygiene products, or emesis in basins. ${ }^{[8,15,16]}$ In this regards, Carr and Goldwire (2008) ${ }^{[16]}$ found that from their observations, the basin is used as a receptacle for emesis and/or as a storage bin for patient care items such as urinals, specimen containers, bathing supplies (including wet items such as bar soap), linen, oral care supplies, dressing supplies and even clothing. 
The results of the current study may be attributed to lack of knowledge, as nurses may not believe that basins may be a source and/or a reservoir for microorganisms. In addition, using a disposable basin for each patient may be costly compared with basins re-use even basins re-use can transmit microorganism from patient to the basin and back to the patient.

\subsubsection{Cleansing products}

soap and water are often used for bed-bath. Studies reported that wash water should be changed whenever it becomes too soapy, cold or dirty, and should always be changed after washing the genitals, buttocks and anal area. ${ }^{[17-23]}$ In the current study, soap and water were used for bed-bath patients in ICUs. This result may be attributed to that nurses used to perform bed-bath from their nursing schools using soap and water. In addition to, nurses' perception that soap and water are effective in cleansing and removing dirt. Deficient of resources are reasons for improper bathing practice.

However, many studies found up to $68.1 \%$ of ICU water samples positive for pseudomonas aeruginosa and nearly fifty percent of patients' infections were because of presence of bacteria in the water supply. ${ }^{[17,18,24,25]}$ In a study of nine hospitals were supplied by different water sources, about one-third of the HAIs were matched to the organisms found in hospital's water supply. Both gram-negative and grampositive organisms were identified in bath water sampled after patients received a soap-and-water basin bath. This is the same number of bacteria found in urine samples of patients with urinary tract infections (UTIs). ${ }^{[9]}$ Therefore, elimination of environmental reservoirs, e.g., the bath basin and nebulizer, are strongly recommended by centers for disease control and prevention. Other studies recommend reducing high-risk patients' exposure to tap water using bottled water, prepackaged disposable bathing products, and faucet water filters. ${ }^{[17,18,23-25]}$

In the current study, soap and water were used for bathing and no cleansing products were used. Cleansing products should have a $\mathrm{pH}$ as close as possible to the 4.5 to $5.5 \mathrm{pH}$ of natural skin. When the skin layer is altered or physical, irritation occurs and the water-holding capacity of skin is affected. It will compromise the skin normal barrier for bacterial colonization and contribute to dry skin. A thinning of the subcutaneous layer occurs, and fewer protective oils are present. These conditions affect the capacity of the skin to act as a barrier against irritants and pathogens. ${ }^{[1]}$

All patient bed-baths in this study were performed with soap or liquid soap and a basin of water. The pre-packaged washcloths were not available in the two ICUs. Soap-andwater basin bed-bath was compared with nonmedicated- prepackaged bed-bath in many studies. ${ }^{[20-23]}$ Forty patients received both types of baths on different days in a surgical, medical, and cardiothoracic ICU. The quality and skin microbial scores were similar, but the prepackaged bed-bath resulted in the use of significantly less product, a reduction in time to gather supplies and perform the bath, lower cost, and higher nurse satisfaction. ${ }^{[20-23]}$ However, the results in this study revealed that water was not changed during most traditional baths, and washcloths were reused from contaminated regions.

However, a study compared fifty traditional baths with fifty medicated-prepackaged baths, which were given to patients in a coma. Nurses in the study had higher satisfaction with prepackaged bed-bath and described greater skin softness, ease of administration with this type of bed-bath. In addition, a lower cost with prepackaged bed-bath compared with soap and water bed-bath. ${ }^{[7]}$ When ICUs transferred from basin bed-bath to prepackaged bed-bath, a decrease in urinary tract infections (UTIs). ${ }^{[11,25]}$ However, using prepackaged bed-bath is costly, one hospital was replaced prepackaged bed-bath with soap-and water basin bed-bath to reduce costs, a significant increase in UTIs was observed. ${ }^{[25]}$

Recent evidence supports that chlorhexidine, impregnated cloths in reducing pathogen transmission. ${ }^{[10,21-23,26-31]} \mathrm{A}$ comprehensive study examined VRE colonization rates with three types of bed-bath (soap and water, non-medicated prepackaged bed-bath, and CHG-impregnated prepackaged cloths). The CHG-impregnated cloths produced colony count reduction on the skin when compared with soap-and-water bed-bath and a significant reduction in CLABSIs was demonstrated with CHG bed-bath. ${ }^{[27]}$ A study comparing CHG cloth bed-bath with non-antimicrobial basin-less cloth bedbath showed, the rate of multidrug resistance organisms (MDRO) acquisition, UTIs and hospital-associated bloodstream infections was lower 5.10 with CHG cloth bed-bath than with non-antimicrobial cloth bed-bath. ${ }^{[28]}$

The current study findings revealed that the majority of nurses rub skin vigorously during bed-bath. The reason for this may be attributed to nurses believe that rubbing increase patient cleanliness. The other reason for this is delegating bed-bath procedure to assistants. Rubbing the skin during bathing play a role in transmitting infections because rubbing results in the large removal of surface epithelial cells that are released into the bath water. The skin flora of hospitalized patients differs with more antibiotic-resistant organisms and a larger presence of gram-negative bacilli. ${ }^{[9]}$

In the current study, an emollient was not applied for all patients after bathing. In a study of bed-bath practices, the researchers found that $64.4 \%$ of patients did not receive an 
emollient after a basin bath. ${ }^{[2]}$ The washcloths used mainly have rough surfaces; therefore, they increase the amount of trans-epidermal water loss and increase dry skin. ${ }^{[6]}$ Some patients had dry skin and need an emollient after bathing; the results of the current study may be due to lack of resources.

Factors affecting bed-bathing practices having knowledge is essential to accomplish a successful hygiene practice. Nurses in the current study have poor bed-bath practices and knowledge. This may be attributed to lack of knowledge, supervision among staff and nurses may give priority for advanced practice rather than basic procedures. Mamhidir et al. (2010) ${ }^{[32]}$ supported these results and stated that having information and knowledge about infection transmission is leading to a higher compliance with hygiene practice and routines. According to Abela and Borg (2012), ${ }^{[33]}$ nursing staff should be continuously educated and suggested posters to be combined with educational sessions for the staff to impact positively on the compliance to hygiene routines. In addition, Wu et al. (2013) $)^{[34]}$ stated that if nurses are aware of infection transmission they will be more motivated to follow hygiene routines than others will. Skår (2009) ${ }^{[35]}$ reported that the use of experienced nurses' knowledge in everyday nursing practice contributes significantly to the quality of health care.

Nurses in the current study reported that there are reasons that affect the bed-bath practices which are financial resources, lack of equipment, no policy; lack of knowledge, workload. These results are in agreement with Coyer et al. (2011) ${ }^{[2]}$ study results who found that workload and organizational factors affect bed-bath practices. The study also, agreed that less experienced nurses followed the routine of care in the ICU, which may not be patient-centered care. Lindh et al. $(2013)^{[38]}$ agreed with the results of the study and stated that lack of equipment has a direct impact on the adherence to hygiene routines. ${ }^{[36]}$

Mills (2011) ${ }^{[37]}$ found that financial resources often have a great influence on the availability of equipment. Takahashi and Turale (2010) ${ }^{[38]}$ point out the need for specialized nurses in health-care hygiene who will be able to translate theory into practice and be a leader for the rest of the staff in caring for patients. Lind et al. (2013) ${ }^{[36]}$ stated that presence of skilled nurses in hygiene practice has a positive effect on hygiene routines compliance among the staff. The reasons for the results in the current study may be because bed-bath is a basic procedure and all nurses expect that it is an easy every day procedure and they are aware of it. Workload plays an important factor affecting bed-bath practices because nurses may delegate the procedure of bed bath to non-nursing personnel that can lead to infections. In addition, nurses used to follow the routine of care and did not know or neglect the results of the evidence-based studies regarding bed-bath practice.

\section{CONCLUSION AND RECOMMENDATIONS}

This study has described an important basic nursing care that is bed-bath practice in critically ill patient. Although, bed-bath is a routine nursing procedure, critical care nurses in the current study had poor skills and knowledge regarding it. Factors affecting bed-bath practice as reported by nurses were financial resources, lack of equipment, no policy, lack of knowledge, workload.

This study has implications for clinical practice and nursing research. Bed-bath is a routine nursing care; many nurses understand that bathing is just for cleaning. Therefore, inservice training program should be conducted for nurses regarding putting priority of nursing care, determining timing, frequency for the bed-bath and prevention of infections during bathing. It is important for the organization to develop a protocol for bed-bath of critically ill patients to be applicable in the settings. Basins used for bathing can be replaced by towels or prepackaged clothes used individually for each patient and disposed after use. Further research is necessary to determine the appropriate timing of bed-bath and other patient care activities. Studies are needed to determine the effect of bed-bath on patients' outcomes such as sleep disturbance, infection and other stressors in ICU. There is a need for further research on the efficacy of disposable bed-bath products such as pre-packaged cloths.

\section{CONFLicts OF INTEREST Disclosure}

The authors declare that there is no conflict of interest.

\section{REFERENCES}

[1] Grealy B, Chaboyer W. Essential nursing care of the critically ill patient. In: Elliott D, Aitken L, Chaboyer W, eds. ACCCN's Critical Care Nursing. 2nd ed. Sydney, Australia: Elsevier-Mosby Australia; 2012: 105-32.

[2] Coyer F, O'Sullivan J, Cadman N. The provision of patient per- sonal hygiene in the intensive care unit: A descriptive exploratory study of bed-bathing practice. Aust Crit Care. 2011; 24(3): 198209. PMid:20829060 http://dx.doi.org/10.1016/j .aucc. 20 10.08 .001

[3] Celik S, Oztekin D, Akyolcu N, et al. Sleep disturbance: The patient care activities applied at the night shift in the intensive 
care unit. J Clin Nurs. 2005; 14(1): 102-106. PMid:15656854 http://dx.doi.org/10.1111/j.1365-2702.2004.01010.x

[4] Cho S, Yun S. Bed-to-nurse ratios, provision of basic nursing care, and in-hospital and 30-day mortality among acute stroke patients admitted to an intensive care unit: cross-sectional analysis of survey and administrative data. Int J Nurs Stud. 2009; 46(8): 1092101. PMid:19268287 http://dx.doi.org/10.1016/j.ijnurst u. 2009.02.001

[5] Tamburri L, DiBrienza R, Zozula R, et al. Nocturnal care interventions with patients in critical care units. Am J Crit Care. 2004; 13(2): 102-12. PMid: 15043238

[6] Voegeli D. The effect of washing and drying practices on skin barrier function. J Wound Ostomy Continence Nurs. 2008; 35(1): 8490. PMid:18199943 http://dx.doi.org/10.1097/01. WON.00 $00308623.68582 . d 7$

[7] Sucre M, De Nicola A. Economic comparison of the traditional bathing method with the basinless bathing method in coma patients. Crit Care. 2009; 13(suppl 1): 459. http://dx. doi .org/10.1186 /cc7623

[8] Johnson D, Lineweaver L, Maze L. Patients' bath basins as potential sources of infection: a multicenter sampling study. American Journal of Critical Care. 2009; 18(1): 31-40. PMid:19116402 http://dx.doi.org/10.4037/ajcc2009968

[9] Marchaim D, Taylor A, Hayakawa K, et al. Hospital bath basins are frequently contaminated with multidrug-resistant human pathogens. Am J Infect Control. 2012; 40(6): 562-4. PMid:22177667 http: //dx.doi.org/10.1016/j.ajic.2011.07.014

[10] Derde L, Dautzenberg M, Bonten M. Chlorhexidine body washing to control antimicrobial-resistant bacteria in intensive care units: A systematic review. Intensive Care Med. 2012; 38(6): 931-9. PMid:22527065 http://dx.doi.org/10.1007/s00134-012-2 $542-z$

[11] Hamman H. Goodbye UTIs: Removal of traditional basin bathing methods leads to $78 \%$ reduction in UTIs. Presented at: NADONA Annual Conference, July 16-20, 2011; Orlando, FL.

[12] Sereika SM, Tate JA, DiVirgilio-Thomas D, et al. The association between bathing and weaning trial duration. Heart Lung. 2011; 40(1): 41-8. PMid:20561879 http://dx.doi.org/10.1016/j.hrtlng. 2010.03 .005

[13] American Association of Critical-Care Nurses. AACN updates patient bathing practices. 2013.

[14] Lima D, Lacerda R. Hemodynamic oxygenation effects during the bathing of hospitalized adult patients critically ill: systematic review. Acta Paul Enferm. 2010; 23(2): 278-85. http://dx.doi .org/10 1590/S0103-21002010000200020

[15] Fanci R, Bartolozzi B, Sergi S, et al. Molecular epidemiological investigation of an outbreak of Pseudomonas aeruginosa infection in an SCT unit. Bone Marrow Transplant. 2009; 43(4): 335-8. PMid:18850015 http://dx.doi.org/10.1038/bmt.2008.319

[16] Goldwire R, Carr D. Hospital basin baths —are our patients at risk. Managing Infection Control. 2008; 48-50.

[17] Cervia J, Canonica F, Ortolano G. Water as a source of health careassociated infections. Arch Intern Med. 2007; 167(1): 92-3.

[18] Clarke A. Nosocomial infections and bath water: Any cause for concern? Clinical Nurse Specialist, 2006; 20(3): 119-23. http: //dx.doi.org/10.1097/00002800-200605000-00006

[19] Hodgkinson B, Nay R, Wilson J. A systematic review of topical skin care in aged care facilities. J Clin Nurs. 2007; 16(1): 129-36. PMid:17181674 http://dx.doi.org/10.1111/j.136 5-2702.2006.01723.x

[20] O'Neill S, Jones T, Lewis M. Nursing works: The application of lean thinking to nursing processes. J Nurs Adm. 2011; 41(12): 546-
52. PMid:22094620 http://dx.doi.org/10.1097/NNA . 0b013 e3182378d37

[21] Montecalvo M, McKenna D, Yarrish R, et al. Chlorhexidine bathing to reduce central venous catheter-associated bloodstream infection: Impact and sustainability. Am J Med. 2012; 125(5): 50511. PMid:22482848 http://dx.doi.org/10.1016/j.amjmed. 2011.10 .032

[22] Karki S, Cheng AC. Impact of non-rinse skin cleansing with chlorhexidine gluconate on prevention of healthcare-associated infections and colonization with multi-resistant organisms: A systematic review. J Hosp Infect. 2012; 82(2): 71-84. PMid:22889522 http: //dx.doi.org/10.1016/j.jhin.2012.07.005

[23] O'Horo J, Silva G, Munoz-Price L, et al. The efficacy of daily bathing with chlorhexidine for reducing healthcare-associated bloodstream infections: A metaanalysis. Infect Control Hosp Epidemiol. 2012; 33(3): 257-67. PMid:22314063 http://dx . doi . org/10.1086/6 64496

[24] Wolcott RD, Ehrlich GD. Biofilms and chronic infections. JAMA 2008; 299(22): 2682-4. PMid:18544729 http://dx.doi.org/10. 1001/jama.299.22.2682

[25] McGuckin M, Shubin A, Hujcs M. Interventional patient hygiene model: Infection control and nursing share responsibility for patient safety. Am J Infect Control. 2008; 36(1): 47, 59-62.

[26] Huang S, Septimus E, Kleinman K, et al. Randomized evaluation of decolonization vs. universal clearance to eliminate methicillinresistant Staphylococcus aureus in ICUs (REDUCE MRSA Trial) Presented at: IDWeek 2012 (first annual joint meeting of IDSA, SHEA, HIVMA, and PIDS); October 17-21, 2012; San Diego, CA. SHEA Lectureship Abstract 36049

[27] Bleasdale S, Trick W, Gonzalez I, et al. Effectiveness of chlorhexidine bathing to reduce catheter-associated bloodstream infections in medical intensive care unit patients. Arch Intern Med. 2007; 167(19): 2073-9. PMid:17954801 http://dx.doi.org/10.1001/archi nte.167.19.2073

[28] Climo MW, Yokoe DS, Warren DK, et al. Effect of daily chlorhexidine bathing on hospital-acquired infection. N Engl J Med. 2013; 368(6): 533-42. PMid:23388005 http://dx.doi.org/10.1056 /NEJMoa1113849

[29] Edmiston C, Krepel C, Seabrook G, et al. Perioperative shower revisited: Can high topical antiseptic levels be achieved on the skin surface before surgical admission? J Am Coll Surg. 2008; 207(2): 233-9. PMid:18656052 http://dx.doi .org/10.1016/j.jamco llsurg. 2007.12.054

[30] Popovich K, Lyles R, Hayes R, et al. Relationship between chlorhexidine gluconate skin concentration and microbial density on the skin of critically ill patients bathed daily with chlorhexidine gluconate. Infect Control Hosp Epidemiol. 2012; 33(9): 889-96. PMid:22869262 http://dx.doi.org/10.1086/667371

[31] Powers J, Peed J, Burns L, et al. Chlorhexidine bathing and microbial contamination in patients' bath basins. AJCC. 2012; 21(5): 338-42 PMid:22941707 http://dx.doi.org/10.4037/ajcc2012242

[32] Mamhidir A, Lindberg M, Larsson R, et al. Deficient knowledge of multidrug resistent bacteria and preventive hygiene measures among primary health care personnel. Journal of Advanced Nursing. 2010; 67(4): 756-62. PMid:21198802 http://dx.doi .org/10.1111/j .1365-2648.2010.05533.x

[33] Abela N, Borg M. Impact on hand hygiene compliance following migration to a new hospital with improved resources and the sequential introduction of World Health Organization recommendation. American Journal of Infection Control. 2012; 40: 737-41. PMid:22285712 http://dx.doi.org/10.1016/j.ajic.2011.09.012 
[34] Wu K, Lee S, Chen J, et al. Hand Hygiene among patients, attitudes, perceptions and willingness to participate. American Journal of Infection Control. 2013; 41: 327-31. PMid:23062662 http: //dx.doi.org/10.1016/j.ajic.2012.03.033

[35] Skår R. Knowledge use in nursing practice: The importance of practical understanding and personal involvement. Nurse Education Today. 2009; 30: 132-6. PMid:19631424 http://dx.doi.org/10.1016 /j.nedt.2009.06.012

[36] Lindh M, Kihlgren A, Perseius K. Factors influencing to hygiene routines in community care - the viewpoint of medically responsible nurses in Sweden. Skandinavian Journal of Caring science. 2013;
27: 224-30. PMid:22676494 http://dx.doi.org/10.1111/j.1 471-6712.2012.01022.x

[37] Mills A. Health Systems in Low- and Middle-Income Countries. Oxford2011: The Oxford handbook of Health Economics. Available from: http://www.oxfordhandbooks.com/view/10.1093/o xfordhb/9780199238828.001.0001/oxfordhb- 978019923 $8828-e-3$

[38] Takahashi I, Turale S. Evaluation of individual and facility factors that promote hand washing in aged care facilities in Japan Nursing and Health Science. 2010; 12(1): 127-34. PMid:20487336 http://dx.doi.org/10.1111/j.1442-2018.2009.00509.x 